\section{Antibiotic Prophylaxis for Dentistry is Not Associated with Fatal Anaphylaxis}

Editor - In a recent issue of Clinical Medicine \& Research, Gopalakrishnan et $\mathrm{al}^{1}$ analyzed the American Heart Association (AHA) ${ }^{2}$ and the National Institute for Health and Clinical Excellence (NICE) ${ }^{3}$ guidelines for the prevention of infective endocarditis (IE) utilizing antibiotic prophylaxis. After reviewing these documents as well as others dealing with methods of preventing IE, they concluded that adverse events stemming from antibiotic use exceeded the benefits of antibiotic prophylaxis. Unfortunately they bolstered their argument by stating that there is "the risk... albeit infrequent [of]...anaphylaxis."1

In fact, the AHA report unequivocally states just the opposite. The AHA statement found on pages 1743-1744 specifically notes:

For 50 years, the AHA has recommended a [form of] penicillin as the preferred choice for dental prophylaxis for IE. During these 50 years, the Committee is unaware of any cases reported to the AHA of fatal anaphylaxis resulting from the administration of a [form of] penicillin recommended in the AHA guidelines for IE prophylaxis. The Committee believes that a single dose of amoxicillin or ampicillin is safe and is the preferred prophylactic agent for individuals who do not have a history of type I hypersensitivity reaction to a penicillin, such as anaphylaxis, urticaria, or angioedema. ${ }^{2}$

Furthermore, the NICE clinical guidelines report specifically notes on page 76 that "The studies included in this review that considered antibiotic prophylaxis against IE did not...identify any episodes of anaphylaxis."3

Gopalakrishnan et $\mathrm{al}^{1}$ are entitled to espouse their opinions relative to the appropriateness, or lack thereof, of administering antibiotics prophylactically to prevent endocarditis, but they should not raise the specter of anaphylaxis in defense of their position.

\section{References}

1. Gopalakrishnan PP, Shukla SK, Tak T. Infective endocarditis: rationale for revised guidelines for antibiotic prophylaxis. Clin Med Res 2009;7:63-68.
2. Wilson W, Taubert KA, Gewitz M, Lockhart PB, Baddour LM, Levison M, Bolger A, Cabell CH, Takahashi M, Baltimore RS, Newburger JW, Strom BL, Tani LY, Gerber M, Bonow RO, Pallasch T, Shulman ST, Rowley AH, Burns JC, Ferrieri P, Gardner T, Goff D, Durack DT; American Heart Association Rheumatic Fever, Endocarditis, and Kawasaki Disease Committee; American Heart Association Council on Cardiovascular Disease in the Young; American Heart Association Council on Clinical Cardiology; American Heart Association Council on Cardiovascular Surgery and Anesthesia; Quality of Care and Outcomes Research Interdisciplinary Working Group. Prevention of infective endocarditis: guidelines from the American Heart Association: a guideline from the American Heart Association Rheumatic Fever, Endocarditis, and Kawasaki Disease Committee, Council on Cardiovascular Disease in the Young, and the Council on Clinical Cardiology, Council on Cardiovascular Surgery and Anesthesia, and the Quality of Care and Outcomes Research Interdisciplinary Working Group. Circulation 2007:116:1736-1754. Erratum in: Circulation 2007;116:e376-377.

3. National Institute for Health and Clinical Excellence. NICE Clinical guideline 64 (CG64). Issued March 2008.

Prophylaxis against infective endocarditis. Antimicrobial prophylaxis against infective endocarditis in adults and children undergoing interventional procedures. Available at: http://www.nice.org.uk/CG064. Accessed initially on October 20, 2009; Re-accessed on June 15, 2010.

Arthur H. Friedlander, DMD Professor-in-Residence Oral and Maxillofacial Surgery, University of California Los Angeles (UCLA) Dental School, and Director of Quality Assurance: Hospital Dental Service, Ronald Reagan Medical Center at UCLA, and Associate Chief of Staff/Director of Graduate Medical Education, VA Greater Los Angeles Healthcare System, 11301 Wilshire Blvd, Los Angeles, California USA Tel: 310-268-3196

Fax: 310-268-4631 Email:arthurffreidlander@med.va.gov 